\title{
PEMBENTUKAN HABITS OF MIND SISWA MELALUI PEMBELAJARAN SALINGTEMAS PADA MATA PELAJARAN FISIKA
}

\author{
Nurmaulita \\ SMANegeri I Tanah Jawa \\ Email:maulitanur2007@gmail.com
}

\begin{abstract}
Abstrak. Habits of mind merupakan kemampuan siswa untuk mengontrol perilaku positif agar memiliki rasa percaya diri dan berkepribadian mantap. Dalam pembelajaran fisika habits of mind sangat penting untuk membentuk karakter belajar siswa yang positif. Penelitian ini bertujuan membentuk kemampuan habits of mind melalui penerapan pendidikan karakter pada mata pelajaran fisika di SMA Negeri I Tanah Jawa. Hasil penelitian menunjukkan bahwa habits of mind siswa 1). Self Regulated Thingking adalah cukup baik, yaitu kemampuan siswa untuk "Menyadari jalan pikirannya sendiri" mencapai $100 \%$, "Membuat rencana yang efektif" mencapai $100 \%$ dan "Kemampuan mencari informasi" mencapai 87,50\%. 2) Sedangkan Critical Thinking yaitu "Mengupayakan keakuratan" mencapai 90,63\%, "Berpandangan terbuka" mencapai 43,75\%, dan "Menghindari perilaku tanpa difikirkan" mencapai 93,75\%. 3) Kemampuan Creative Thingking adalah "Mengupayakan menyelesaikan tugas" mencapai 93,75\%, "Mendorong sesuatu yang diyakini tidak dapat mengerjakannya" mencapai $81,25 \%$, dan "Menemukan solusi sendiri terhadap masalah" mencapai $84,38 \%$. Selanjutnya kemampuan habits of mind guru yang belum dikembangkan adalah "Mendorong siswa menyadari dan menggunakan sumber-sumber informasi yang perlu" dan "Mendorong siswa berpandangan terbuka" serta "Mendorong siswa menemukan solusi sendiri terhadap masalah". Disarankan kemampuan Critical Thinking guru masih perlu diperbaiki. Kemampuan Creative Thingking guru kurang maksimal dilakukan. Sehingga pada penelitian selanjutnya perlu dilakukan pembimbingan dan dorongan agar siswa termotivasi membuat dan memikirkan cara pandang yang inovatif dan kreatif dalam menemukan ide baru untuk diterapkan dalam kehidupan nyata.
\end{abstract}

Kata kunci: pendidikan karakter, habits of mind

\section{THE FORMING STUDENTS' HABBITS OF MIND THROUGH SALINGTEMAS LEARNING ON PHYSICS}

\author{
Nurmaulita \\ SMANegeri I Tanah Jawa \\ Email:maulitanur2007@gmail.com
}

\begin{abstract}
Habits of mind are the ability to control the positive behavior of students in order to have the confidence and steady personality. In physics learning habits of mind is very important to establish the character of positive student learning. The objectives in this study to establish the ability of habits
\end{abstract}


of mind through the implementation of character education in physics in the SMA Negeri 1 Tanah Jawa. The results showed that the habits of mind students 1) Self Regulated Thingking is pretty good, which is the ability of students to "Be aware of the way his own mind" reaches $100 \%$, "Creating an effective plan" reaches $100 \%$ and the "ability to find information" reaches $87.50 \%$. 2) While Critical Thinking is "Striving for accuracy" reaches 90.63\%, "Open-minded" reaches 43.75\%, and "Avoiding behavior without rethinking" reaches $93.75 \%$. 3) Creative ability Thingking is "Striving for completing the task" reaches $93.75 \%$, "Pushing something that is believed to not be able to do" to reach $81.25 \%$, and "Finding your own solutions to the problem of" reaching $84.38 \%$. Furthermore, the ability of the teacher habits of mind that have not been developed is "Encouraging students to recognize and use the resources necessary information" and "Encouraging students openminded" and "Encouraging students to find their own solution to the problem". Critical Thinking teacher advised capabilities still need to be improved. Creative ability Thingking teachers made less than the maximum. So that in further research needs to be done coaching and encouragement so that students are motivated to create and innovative thinking perspective and creative in finding new ideas to apply in real life.

\section{Keywords: character education, habits of mind}

\section{PENDAHULUAN}

Pembelajaran fisika sebagai salah satu bagian ilmu sains yang pada hakikatnya terdiri dari sains sebagai produk dan sains sebagai proses. Bagian sains sebagai produk meliputi kumpulan pengetahuan fakta, konsep dan prinsip sains. Sedangkan sains sebagai proses meliputi keterampilan dan sikap positif yang dimiliki peserta didik untuk mencapai produk sains.

Sikap peserta didik untuk mencapai produk sains dapat ditempuh dengan sikap ilmiah dan kebiasaan berfikir aktif dalam pembelajaran. Kebiasaan berfikir positif dalam kegiatan belajar mengajar ini dapat membentuk habits of mind siswa untuk mencapai keberhasilan belajarnya.

Pembelajaran fisika di kelas memiliki peranan penting dalam pembentukan sikap habits of mind dalam proses pembelajaran dan menciptakan produk sains secara ilmiah. Perilaku peserta didik belajar fisika sebagai habits of mind dapat digambarkan dalam kebiasaan berfikir aktif, berfikir kreatif, dan berfikir kritis bagaimana siswa dapat menghasilkan pengetahuan tidak mereproduksi pengetahuan.
Selama ini, guru yang melaksanakan pembelajaran di kelas menemui beberapa peserta didik yang memiliki kecerdasan intelektual baik namun kurang kemampuan bersikap. Terdapat beberapa peserta didik cerdas dalam penjabaran konsep, cerdas dalam hitungan matematiknya. Namun kurang mampu berkomunikasi dan bekerjasama dengan temannya, tidak memiliki rasa empati, dan jika menemui kesulitan, mudah berputus asa.

Hasil observasi yang dilakukan penulis terdapat permasalahan yang perlu segera dilakukan perbaikan, yaitu: 1) 30\% siswa yang tidak siap kalah saat dilakukan ujian disekolah sehingga menimbulkan rasa berputus asa yang mengakibatkan rendahnya minat dan motivasi siswa, 2) $50 \%$ dalam kegiatan belajar dikelas sering berlaku curang suka mencontek sehingga timbul perilaku yang kurang bertanggung jawab, 3) dilakukan pembelajaran dengan metode kerja kelompok, terdapat $50 \%$ siswa saja yang kurang bersosialisasinya dengan temannya di kelas, 4) $30 \%$ siswa yang hanya menerima pembelajaran dari guru apa adanya, 5) Dalam melaksanakan 
kegiatan belajar mengajar di kelas RPP yang disusun guru juga hanya mencapai tujuan aspek kognitif saja. Permasalahan tersebut apabila dibiarkan dapat menimbulkan permasalahan siswa dalam kehidupan sehari-hari, dan tidak seimbangnya kemampuan intelektual dan cara bersikap dengan karakter yang baik.

Dari uraian masalah di atas, perlu dilakukan perbaikan proses pembelajaran dengan menerapkan pendidikan karakter. Menurut tim Pengembangan Pendidikan Budaya dan Karakter Bangsa (2011) pengertian pendidikan budaya dan karakter bangsa dimaknai sebagai pendidikan yang mengembangkan nilai-nilai budaya dan karakter bangsa pada diri peserta didik. Oleh karena itu, pendidikan karakter diharapkan menjadi suatu proses pendidikan yang dapat mengembangkan watak, tabiat, ahlak atau kepribadian sebagai landasan untuk cara pandang, berfikir, bersikap dan bertindak.

Hasil refleksi yang dilakukan kurang maksimalnya pendidikan karakter karena: 1) Tidak dirancangnya pendidikan karakter disetiap mata pelajaran. 2) Dalam merancang kurikulum tidak mengembangkan nilai-nilai karakter siswa. 3) Sekolah dalam melaksanakan pendidikan karakter hanya dimasukkan dalam kegiatan ekstrakurikuler saja.

Hasil penelitian yang berkaitan tentang habits of mind melalui studi-studi kebiasaan berpikir tentang kemampuan dasar bekerja ilmiah telah dilakukan oleh Rustaman (2008) yang menyatakan bahwa sejumlah kecerdasan emosional tidak secara otomatis terkembangkan melalui pembelajaran sains yang menekankan pada kebiasaan berpikir, melainkan perlu dirancang secara khusus.

Berdasarkan latar belakang masalah ini, rumusan masalahnya adalah bagaimana pelaksanaan penerapan pendidikan karakter melalui pembelajaran salingtemas dapat membentuk kemampuan habits of mind siswa pada mata pelajaran fisika di kelas XI IPA SMA Negeri 1 Tanah Jawa? Tujuannya adalah membentuk kemampuan habits of mind siswa mata pelajaran fisika di SMAN 1 Tanah Jawa melalui penerapan pendidikan karakter.

\section{Pentingnya Pendidikan Karakter}

Tabel.1. Nilai dan deskripsi Nilai Pendidikan Karakter (Badan Penelitian dan Pengembangan Pusat Kurikulum, 2011)

\begin{tabular}{|c|c|c|}
\hline No & $\begin{array}{c}\text { Nilai } \\
\text { karakter }\end{array}$ & Deskripsi \\
\hline 1 & Religius & $\begin{array}{l}\text { Patuh dalam melaksanakan ajaran } \\
\text { agama yang dianutnya. }\end{array}$ \\
\hline 2 & Jujur & $\begin{array}{l}\text { Dapat dipercaya dalam perkataan, } \\
\text { tindakan, dan pekerjaan. }\end{array}$ \\
\hline 3 & Toleransi & $\begin{array}{l}\text { Sikap menghargai perbedaan } \\
\text { agama, suku, etnis dan sikap yang } \\
\text { berbeda dari dirinya. }\end{array}$ \\
\hline 4 & Disiplin & $\begin{array}{l}\text { Perilaku tertib dan patuh pada } \\
\text { berbagai ketentuan dan peraturan. }\end{array}$ \\
\hline 5 & Kerja Keras & $\begin{array}{l}\text { Perilaku sungguh-sungguh dalam } \\
\text { mengatasi hambatan belajar }\end{array}$ \\
\hline 6 & Kreatif & $\begin{array}{l}\text { Melakukan sesuatu untuk meng } \\
\text { hasilkan cara atau hasil baru. }\end{array}$ \\
\hline 7 & Mandiri & $\begin{array}{l}\text { Perilaku yang tidak tergantung } \\
\text { pada orang lain. }\end{array}$ \\
\hline 8 & Demokratis & $\begin{array}{l}\text { Berfikir, bersikap, dan bertindak } \\
\text { yang menilai sama hak dan } \\
\text { kewajiban dirinya dan orang lain. }\end{array}$ \\
\hline 9 & $\begin{array}{l}\text { Rasa Ingin } \\
\text { Tahu }\end{array}$ & $\begin{array}{l}\text { Sikap dan tindakan yang berupaya } \\
\text { mengetahui lebih mendalam dan } \\
\text { luas dari suatu yang dipelajarinya. }\end{array}$ \\
\hline 10 & $\begin{array}{c}\text { Semangat } \\
\text { Kebangsaan }\end{array}$ & $\begin{array}{l}\text { Menempatkan kepentingan bangsa } \\
\text { di atas kepentingan diri. }\end{array}$ \\
\hline 11 & $\begin{array}{l}\text { Cinta Tanah } \\
\text { Air }\end{array}$ & $\begin{array}{l}\text { Sikap yang menunjukkan kese- } \\
\text { tiaan, kepedulian, dan penghar- } \\
\text { gaan yang tinggi terhadap bahasa } \\
\text { sosial, budaya, ekonomi. }\end{array}$ \\
\hline 12 & $\begin{array}{l}\text { Menghargai } \\
\text { Prestasi }\end{array}$ & $\begin{array}{l}\text { Tindakan yang mendorong dirinya } \\
\text { menghasilkan sesuatu yang bergu- } \\
\text { na bagi masyarakat. }\end{array}$ \\
\hline 13 & Komunikatif & $\begin{array}{l}\text { Tindakan yang memperlihatkan } \\
\text { rasa senang bergaul, dan bekerja } \\
\text { sama dengan orang lain. }\end{array}$ \\
\hline 14 & Cinta Damai & $\begin{array}{l}\text { Tindakan yang menyebabkan orang } \\
\text { lain merasa senang dan aman atas } \\
\text { kehadiran dirinya. }\end{array}$ \\
\hline 15 & $\begin{array}{c}\text { Gemar } \\
\text { membaca }\end{array}$ & $\begin{array}{l}\text { Kebiasaan menyediakan waktu } \\
\text { membaca. }\end{array}$ \\
\hline 16 & $\begin{array}{c}\text { Peduli } \\
\text { Lingkungan }\end{array}$ & $\begin{array}{l}\text { Tindakan yang selalu berupaya } \\
\text { mencegah kerusakan pada ling- } \\
\text { kungan alam sekitarnya. }\end{array}$ \\
\hline 17 & $\begin{array}{l}\text { Peduli } \\
\text { Sosial }\end{array}$ & $\begin{array}{l}\text { Tindakan yang selalu ingin } \\
\text { memberi bantuan pada orang lain. }\end{array}$ \\
\hline 18 & $\begin{array}{l}\text { Tanggung } \\
\text { Jawab }\end{array}$ & $\begin{array}{l}\text { Perilaku untuk melaksanakan } \\
\text { tugas kewajiban nya terhadap diri } \\
\text { masyarakat, lingkungan. }\end{array}$ \\
\hline
\end{tabular}




\section{Habits Of Mind}

Habits of mind dapat dikatakan sebagai kebiasaan berfikir. Habits of mind siswa merupakan kemampuan siswa untuk mengontrol perilaku positifnya. Menurut Marzano dalam Chaerun (2005), kebiasaan berfikir terdiri dari tiga komponen yaitu pengaturan diri (self regulation), berfikir kritis (critical thinking), dan berfikir kreatif (creative thinking).

Tabel 2. Karakteristik Habits of Mind

\begin{tabular}{|c|c|c|}
\hline No & Habits Of Mind & Deskription \\
\hline 1 & $\begin{array}{c}\text { Persisting } \\
\text { (Mampu bertahan) }\end{array}$ & $\begin{array}{l}\text { Tekun dalam tugas. } \\
\text { Tidak mudah menyerah. } \\
\text { Tahan menghadapi resiko. }\end{array}$ \\
\hline 2 & Managing impulsivity & $\begin{array}{l}\text { Mampu bertindak dengan } \\
\text { baik. Dorongan hati sesaat. }\end{array}$ \\
\hline 3 & $\begin{array}{c}\text { Listening with } \\
\text { understanding and } \\
\text { empathy }\end{array}$ & $\begin{array}{l}\text { Mampu mendengarkan } \\
\text { orang lain. Berempati } \\
\text { terhadap orang lain }\end{array}$ \\
\hline 4 & Thinking flexibly & $\begin{array}{l}\text { Berfikir fleksibel bukan } \\
\text { berarti tidak disiplin } \\
\text { melainkan tidak kaku. }\end{array}$ \\
\hline 5 & Metacognition & $\begin{array}{l}\text { Berlatih memaksimalkan } \\
\text { otak dengan konsentrasi. }\end{array}$ \\
\hline 6 & Striving For Accuracy & $\begin{array}{l}\text { Kemampuan untuk tidak } \\
\text { berbohong. }\end{array}$ \\
\hline 7 & $\begin{array}{c}\text { Question and posing } \\
\text { problem }\end{array}$ & $\begin{array}{l}\text { Kemampuan memiliki rasa } \\
\text { ingin tahu. Menemukan } \\
\text { pemecahan masalah deng- } \\
\text { an bertanya. }\end{array}$ \\
\hline 8 & $\begin{array}{l}\text { Applying New } \\
\text { Knowledge to New } \\
\text { Situation }\end{array}$ & $\begin{array}{l}\text { Menerapkan pengetahuan } \\
\text { lama pada situasi baru. } \\
\text { Memanfaatkan ilmu dalam } \\
\text { kehidupan. }\end{array}$ \\
\hline 9 & $\begin{array}{c}\text { Thinking And } \\
\text { Comunicating with } \\
\text { Clarity and Precision } \\
\end{array}$ & $\begin{array}{l}\text { Kemampuan berkomuni- } \\
\text { kasi untuk berfikir. }\end{array}$ \\
\hline 10 & $\begin{array}{c}\text { Gathering Data } \\
\text { Through all Sense }\end{array}$ & $\begin{array}{l}\text { Mengumpulkan data deng } \\
\text { an perasaan, pendengaran } \\
\text { dan penglihatan. }\end{array}$ \\
\hline 11 & $\begin{array}{l}\text { Creating, Imagining } \\
\text { and Innovating }\end{array}$ & $\begin{array}{l}\text { Mengembangkan ide-ide } \\
\text { baru dengan menemukan, } \\
\text { menciptakan berimaginasi } \\
\text { sebuah idea tau gagasan.. }\end{array}$ \\
\hline 12 & $\begin{array}{c}\text { Responding with } \\
\text { wonderment and awe }\end{array}$ & $\begin{array}{l}\text { Menanggapi dengan rasa } \\
\text { kekaguman. }\end{array}$ \\
\hline 13 & $\begin{array}{c}\text { Taking responsible } \\
\text { risk }\end{array}$ & $\begin{array}{l}\text { Mampu bertanggung } \\
\text { jawab terhadap resiko. }\end{array}$ \\
\hline 14 & Finding humour & Santai dan Enjoy \\
\hline 15 & $\begin{array}{c}\text { Thinking } \\
\text { interdependently }\end{array}$ & $\begin{array}{l}\text { Mampu bekerjasama deng } \\
\text { an teman lain }\end{array}$ \\
\hline 16 & $\begin{array}{l}\text { Remaining open to } \\
\text { continuous learning }\end{array}$ & $\begin{array}{l}\text { Tidak berhenti belajar. } \\
\text { Mengakui ketidaktahuan. }\end{array}$ \\
\hline
\end{tabular}

\section{Pendekatan Salingtemas}

Pembelajaran fisika dengan pendekatan salingtemas dapat difahami sesuai istilah yang mengandung kata kunci salingtemas yaitu: sains-lingkungan-tekonologi dan masyarakat. Menurut Poedjiadi dalam Mahmuddin (2009), pelaksanaan pendekatan STM dapat dilakukan melalui tiga macam strategi, yaitu:

a. Strategi pertama, menyusun topik yang menyangkut konsep-konsep yang ingin ditanamkan pada peserta didik.

b. Strategi kedua, menyajikan suatu topik yang relevan dengan konsep-konsep tertentu yang termasuk dalam standar kompetensi.

c. Strategi ketiga, mengajak anak untuk berpikir dan menemukan aplikasi konsep sains industri atau produk teknologi di masyarakat di saat kegiatan belajar berlangsung. Tindakan ini dapat dijadikan sebagai tindakan follow up.

\section{METODE PENELITIAN}

Penelitian ini dilakukan di kelas XI IPA SMAN 1 Tanah Jawa dengan tahapan penelitian tindakan kelas dalam dua siklus. Pengamatan kemampuan habits of mind siswa dilaksanakan saat proses belajar mengajar di kelas. Pada penelitian ini kegiatan yang diamati adalah aktivitas proses belajar yang dilakukan guru dan aktivitas siswa yang menggambarkan kemampuan habits of mind siswa. Adapun rangkaian pelaksanaan penerapan pendidikan karakter melalui salingtemas adalah:

1. Perencanaan Pengembangan Karakter

2. Pengembangan Proses Pembelajaran

3. Evaluasi Pendidikan Karakter

Evaluasi hasil belajar pencapaiannya berdasarkan nilai budaya dan karakter yang didasarkan pada indikator pelajaran fisika. Tahap evalusi ditentukan instrumen penelitian untuk mengukur kemampuan habits of mind siswa: (a) Aspek self regulation, (b) Aspek critical thingking, (c) Aspek creative thingking. Hasil penelitian dideskripsikan untuk mengungkap pembentukan habits of mind siswa. 
HASIL PENELITIAN DAN PEMBAHASAN Data Hasil Penelitian Habits Of Mind Siswa

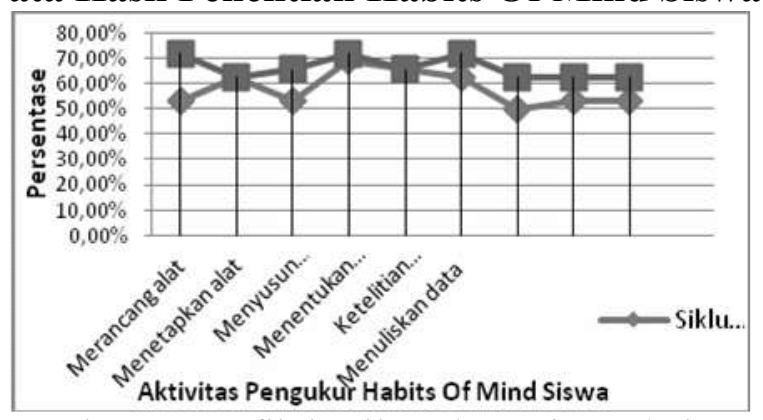

Gambar 2. Grafik hasil Habits of Mind Siswa

\section{Hasil Siklus 1}

Aspek kemampuan kinerja siswa pada siklus 1 mencapai rata-rata persentase berada pada kategori kurang yaitu pada rentangan 57,99\%. Aspek yang masih sulit dicapai siswa adalah Mengolah data hasil percobaan yaitu dalam pencapaian $50,00 \%$. Selanjutnya aspek merancang alat, menyusun hipotesis, menyimpulkan hasil, mengkomunikasikan hasil percobaan mencapai perolehan 53,13\% yaitu berada pada kategori kurang. Aspek kemampuan siswa menetapkan alat/bahan, menentukan langkah kerja, ketelitian mengukur dan menuliskan data percobaan berada pada kategori cukup yaitu berada diatas $61 \%$. Kemampuan habits of mind siswa tentang kinerja siswa dalam pembelajaran fisika hanya dapat dicapai oleh kelompok 2 yaitu pencapaian hasil $63,89 \%$ berada dalam kategori cukup. Sedangkan ketujuh kelompok lain pencapaiannya hanya kurang dari $60 \%$.

\section{Hasil Siklus 2}

Aspek kemampuan kinerja siswa pada siklus 2 mengalami peningkatan yaitu mencapai rata-rata persentase berada pada kategori cukup yaitu pada rentangan 66,32\%. Aspek yang masih sulit dicapai siswa pada siklus 1 yaitu Mengolah data hasil percobaan juga mengalami peningkatan yaitu dalam pencapaian $62,50 \%$.

Selanjutnya setiap aspek untuk menggambarkan habits of mind siswa pada siklus dua ini semua mengalami peningkatan. Aspek kemampuan merancang alat dan menuliskan data percobaan berada pada rentangan $71,88 \%$ kategori baik. Aspek kemampuan siswa menetapkan alat/bahan, menentukan langkah kerja, ketelitian mengukur, mengolah data hasil percobaan, menyimpulkan hasil dan mengkomunikasikan hasil percobaan berada pada kategori cukup yaitu berada diatas $61 \%$.

\section{Habits Of Mind Siswa}

Deskripsi sikap perilaku berfikir siswa dapat digambarkan dalam angket yang disebarkan guru. Hasil angket menunjukkan bahwa kebiasaan berfikir siswa tentang: Self Regulated Thingking adalah 1) Kemampuan Siswa untuk menyadari jalan pikirannya sendiri dapat di ketahui dengan memberikan pertayaan angket kesiswa jika kamu tidak dapat mengerjakan tugas dengan baik, apakah kamu memikirkannya kembali agar dapat menolong kamu menemukan kesalahan dalam menyelesaikan tugas. Keseluruhan siswa (100\%) menjawab "Ya". Selanjutnya habits of mind siswa untuk menggali informasi "Menyadari dan mencari sumber-sumber" diketahui dengan memberi pertanyaan "Apakah kamu mencari sumber informasi pada setiap mengerjakan tugas yang memerlukan sumber informasi?" sebagian siswa menjawab "Ya" sebanyak 87,50\% dan menjawab "Tidak" adalah 12,50\%. Critikal Thinking siswa dapat ditunjukkan dengan 3 angket tentang: 1) "Akurat dan mengupayakan keakuratan", pertanyaan yang di buat kedalam angket adalah "Ketika melakukan perhitungan atau mencatat data hasil observasi, apakah kamu melakukannya dengan teliti? Jawaban siswa yang menjawab "Ya" adalah 90,63\%.

Kemampuan siswa untuk berpandangan terbuka dapat digambarkan dalam pertanyaan angket "Apakah kamu akan berlapang dada ketika ide-ide kamu ditolak? Jawaban siswa Ya adalah 43,75\%, ini menunjukkan bahwa siswa memiliki keegoisan yang tinggi, dan kurang menyadari kelemahan dan ketidak mampuan siswa dalam melakukan suatu pekerjaan.

Kemampuan siswa untuk point 3) Menghindari perilaku tanpa difikirkan, dapat diketahui dengan memberikan pertanyaan "Apakah kamu menjawab pertanyaan langsung tanpa difikirkan terlebih dahulu atau kamu benarbenar mengetahui dasar ilmunya atau hanya 
Nurmaulita: Pembentukan Habits Of Mind Siswa Melalui Pembelajaran Salingtemas Pada Mata Pelajaran Fisika.
Jurnal Pendidikan Fisika

p-ISSN 2252-732X

e-ISSN 2301-7651 asala-asalan? Sebagian siswa menjawab “Tidak" adalah 93,75\%.

Kemampuan Creative Thingking yaitu aspek 1) Mengupayakan terus menerus menyelesaikan tugas meskipun jawabannya belum bisa diduga sudah baik dimiliki oleh siswa. Pertanyaan angket siswa yang mengusahakan secara terus menerus mengupayakan menyelesaikan tugas selalu dilakukan baik oleh siswa, beberapa siswa menjawab "Ya" adalah 93,75\%. Selanjutnya aspek kedua. 2) Mendorong diri sendiri untuk mendorong sesuatu yang diyakininya tidak dapat mengerjakannya" juga memiliki respon yang baik dari siswa dengan memberikan pendapat $81,25 \%$ jawaban "Ya". Kemudian dari pertanyaan angket "Apakah kamu dapat menemukan solusi sendiri terhadap masalah yang sulit atau kamu dihadapkan pada pilihan yang sulit?" hal ini sangat sulit dilakukan, dominan jawaban siswa yang menjawab "tidak" yaitu $84,38 \%$.

\section{Deskripsi Habits Of Mind Guru}

Hasil angket yang diisi guru fisika, menunjukkan bahwa guru berupaya membiasakan berfikir Self Regulated Thingking.

Tabel 4. Deskripsi Habits Of Mind Guru

\begin{tabular}{|c|c|c|}
\hline No & Profile & $\mathbf{Y} / \mathbf{T}$ \\
\hline \multirow[t]{4}{*}{1} & Self Regulated Thingking & \\
\hline & $\begin{array}{l}\text { 1. Membantu siswa menyadari jalan } \\
\text { fikirannya sendiri }\end{array}$ & Ya \\
\hline & $\begin{array}{l}\text { 2. Mendorong siswa membuat rencana yang } \\
\text { efektif }\end{array}$ & $\mathrm{Ya}$ \\
\hline & $\begin{array}{l}\text { 3. Mendorong siswa untuk menyadari dan } \\
\text { menggunakan sumber-sumber yang perlu. }\end{array}$ & Tidak \\
\hline \multirow[t]{4}{*}{2} & Critikal Thinking & \\
\hline & $\begin{array}{l}\text { 1. Mendorong siswa untuk mengupayakan } \\
\text { keakuratan. }\end{array}$ & $\mathrm{Ya}$ \\
\hline & $\begin{array}{l}\text { 2. Mendorong siswa untuk berpandangan } \\
\text { terbuka. }\end{array}$ & Tidak \\
\hline & $\begin{array}{l}\text { 3. Mendorong siswa untuk mencegah sifat } \\
\text { impulsive. }\end{array}$ & $\mathrm{Ya}$ \\
\hline \multirow[t]{4}{*}{3} & Creative Thingking & \\
\hline & $\begin{array}{l}\text { 1. Mendorong siswa terus menerus } \\
\text { mengupayakan menyelesaikan tugas } \\
\text { meslipun jawabannya belum bisa di duga. }\end{array}$ & $\mathrm{Ya}$ \\
\hline & $\begin{array}{l}\text { 2. Mendorong siswa untuk mencoba sesuatu } \\
\text { yang menurutnya tidak yakin dapat } \\
\text { mengerjakannya. }\end{array}$ & $\mathrm{Ya}$ \\
\hline & $\begin{array}{l}\text { 3. Mendorong siswa untuk membuat cara } \\
\text { pandang baru yang berbeda dengan cara } \\
\text { pandang umumnya. }\end{array}$ & Tidak \\
\hline
\end{tabular}

\section{Simpulan}

Kemampuan habits of mind yang dapat dicapai siswa adalah siswa (1) Self Regulated Thingking cukup baik, yaitu kemampuan siswa untuk menyadari jalan pikirannya sendiri mencapai $100 \%$, membuat rencana yang efektif mencapai $100 \%$ dan kemampuan mencari informasi mencapai 87,50\%. (2) Sedangkan Critical Thinking yaitu mengupayakan keakuratan mencapai 90,63\%, berpandangan terbuka mencapai $43,75 \%$, dan menghindari perilaku tanpa difikirkan mencapai 93,75\%. (3) Kemampuan creative thingking adalah mengupayakan menyelesaikan tugas mencapai 93,75\%, mendorong sesuatu yang diyakini tidak dapat mengerjakannya mencapai $81,25 \%$, dan menemukan solusi sendiri terhadap masalah sulit mencapai $84,38 \%$. Selanjutnya kemampuan habits of mind guru yang belum dikembangkan adalah mendorong siswa menyadari dan menggunakan sumber-sumber informasi yang perlu dan mendorong siswa berpandangan terbuka serta mendorong siswa menemukan solusi sendiri terhadap masalah yang sulit.

\section{DAFTAR PUSTAKA}

Chaerun, A. 2005. Penerapan Penilaian Kinerja (Performan Assesment) dalam membentuk habits of Mind Siswa pada Pembelajaran Konsep Lingkungan. Tesis. Bandung: Pasca Sarjana UPI.

Mahmuddin. 2009. Pendekatan Sains, Teknologi, dan Masyarakat dalam Pembelajaran. http://mahmuddin.wordpress.com/2009/1 1/17/pendekatan-sains-teknologi-danmasyarakat-dalam-pembelajaran/. Diakses 29 Mei 2011.

Poedjiadi, A. 2005. Sains Teknologi Masyarakat Model Pembelajaran Kontekstual Bermuatan Nilai. Bandung: Rosdakarya.

Rustaman. N.Y. 2008. Kebiasaan Berfikir Dalam Pembelajaran Sains dan Asesmennya. Bandung: Makalah UPI.

Sumadi. 2011. Pengembangan Pendidikan Budaya dan Karakter Bangsa. Jakarta: Badan Penelitian dan Pengembangan Pusat Kurikulum. 
